\title{
PRODUCTION PLANNING AND CONTROL SYSTEM WITH JUST IN TIME AND LEAN PRODUCTION: A REVIEW
}

\author{
Afriansyah., ${ }^{1,2}$, Mohruni Amrifan Saladin²* \\ ${ }^{1}$ Operation, Pertamina Drilling, Prabumulih, South Sumatera, Indonesia \\ ${ }^{2}$ Mechanical Engineering Department, Sriwijaya University, South Sumatera, Indonesia
}

\begin{abstract}
Manufacturing can be defined as applying physical and/or chemical processes to modify the structure, properties, and appearance of a given starting material to produce parts or products. Manufacturing often entails combining multiple elements for the creation of assembled products. This study aimed to establish a general understanding of development production planning and control and typical products such as just in time and lean production. Method of this study through literature review. This study described activities related to production planning and production control, the difference between lean production and traditional production (push system), and the structure of lean production as known as Toyota system manufacturing.
\end{abstract}

Keywords: PPC, lean production, Just in time production, MRP, MPS

\section{INTRODUCTION}

The term of Production, planning, and control (PPC) is related to encountered logistical problems in the manufacturing processes. The management of the detailed process such as type and amount of the products, time, and acquisition of the raw materials, part, and resources needed for production processes.

PPC solves these logistical problems by managing information [1]. Production planning begins when the customer needs are identified and determines "what" is the product's value for him. The so-called value stream classification or sequence of all processes required to produce a product is carried out based on this data. Developing a process map enables unnecessary processes to be identified and a roadmap for flexible organizational production structure to be developed [2].

Lean manufacturing is a technological paradigm that has been accepted since the early 1990s in many industrial companies [3]. Lean production aims to produce a product that is precisely what the customer wants at the right time, minimizing all non-value-added production activities [3]. Lean production can be explained in a production process as the elimination of waste
[4]. Any (tangible and intangible process or product) that does not add value to the end product is referred to as waste. When the time comes to start leaning on the transformation, management will need to get people together and make them aware of what will happen and what is expected [5].

The lean transition is that a transformation in organizational culture to manage lean is more about managing the change process than managing lean tools and techniques, particularly during the initial phases [6]. Lean production is a socio-technical system [7], considered to be a philosophy that deals with both technical and cultural aspects [8]. The efficiency of manufacturing has been an objective in the development of the Toyota Production System (TPS) [9].

JIT was introduced in time concept making Toyota as its product component in Japan. JIT is a system whether the company starts to manufacture/buy once the customer orders the good to make zero inventories effectively. In other words, materials are purchased and produced as and when they are needed in a JIT environment. The whole idea is based on the concept that items are delivered just as advertised when the consumer places the order [10]

*Corresponding author's email: mohrunias@unsri.ac.id 
JIT is a Japanese philosophy of management that has been applied in many Japanese manufacturing organizations since the early 1970s. In the Toyota manufacturing plants, it was first developed and perfected by Taiichi Ohno as a means of meeting consumer demands with minimal delays. For this reason, Taiichi Ohno is frequently referred to as the father of JIT.

\section{METHODOLOGY/ EXPERIMENTAL}

Methodology for this paper based on review book and literature review. Production planning and control can be described based on flow chart in Figure 1. The activities of PPC are categorized as production planning (aggregate production planning, master production planning, material requirements planning, capacity planning) and production control (shop floor control, inventory control, manufacturing resources planning, enterprise resource planning).

Just in time production (JIT) is part of lean production system (as known as toyota production system). It is depict on figure 2 . The ingredients of lean production are just in time production and automation, base structure is elimination of waste in production operations, goal focus on customer, and worker involvement

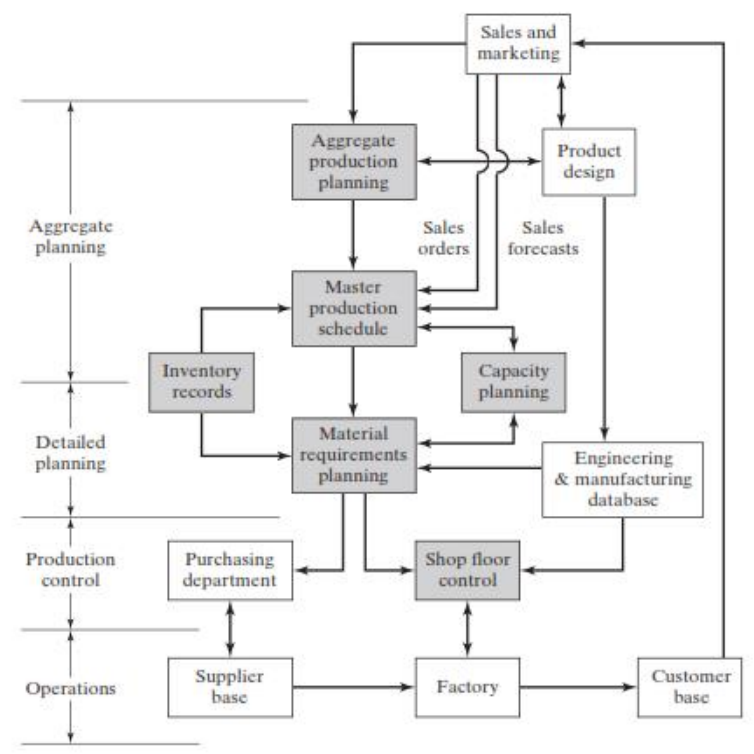

Figure 1 Activities in PPC system

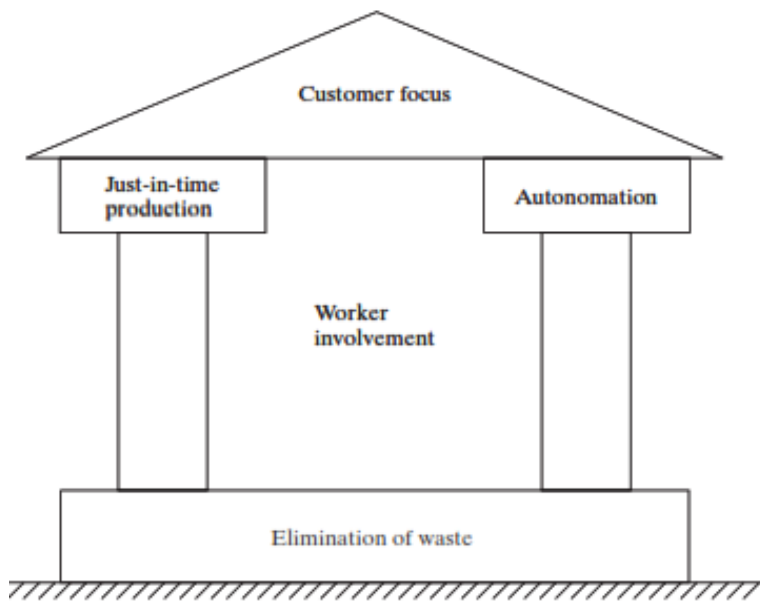

Figure 2 Structure of lean production system

\section{RESULTS AND DISCUSSION}

\subsection{Production planning and control system}

Production planning and control (PPC) is concerned with the logistics problems that are encountered in manufacturing, that is, managing the details of what and how many products to produce and when, and obtaining the raw materials, parts, and resources to produce those products. PPC solves these logistics problems by managing information. PPC is the integrator in computer integrated manufacturing.

\subsubsection{Agregate production planning}

It is a activities that coordinate planning the production output level for the major product lines of the company. The aggregate plan must be coordinated with plans of sales and marketing department because its related to the product in currently production, presents and future inventory levels, and new product.

\subsubsection{Master production schedule}

Master production schedule is specific plan of the quantities to be produced of individual models within each product line. The production quantities of major product line from aggregate plan must be converted into master production schedule (MPS) or master schedule.

Product included in the MPS divide into three categories: firm customer order, forecasted demand, and spare parts.

\subsubsection{Material requirements planning}

Material requirements planning is a planning technique that involve computer which convert 
the master schedule for end products into detailed schedule for the raw materials and components used in the end products. Concepts of MRP are relatively straightforward and determined quantities of dependent demand items.

MRP input system included: master production schedule, bill of materials file and other engineering and manufacturing data, inventory record file. Figure 3 showed the flow of data into MRP processors and its conversion into useful output report.

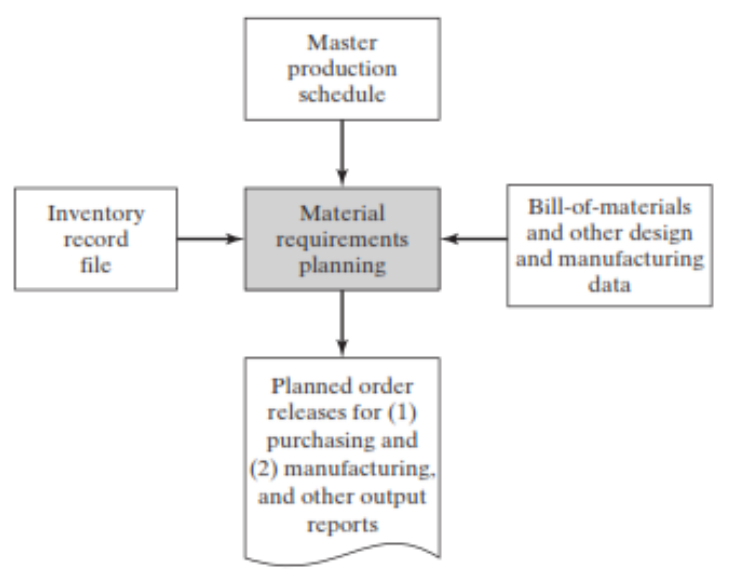

Figure 3 structure of MRP system

The types of data contained in the inventory record are categorized: item master data, inventory status, and subsidiary data. The MRP processor operates on MPS, BOM, and inventory record file data. The master schedule specifies the list of final products required for each period of time, the BOM defines which materials and components are needed for each product, and the inventory record file provides the current and future inventory status of each product, component, and material. The MRP processor determines how many components and raw materials are required for each cycle by "exploding" the specifications of the end product into successively lower levels in the structure of the product.

The MRP software provides a range of inputs that can be used in scheduling and plant operations management. The inputs include (1) scheduled order releases approving the placement of orders expected by the MRP system, (2) announcements of planned order releases in future periods, (3) rescheduling notices suggesting changes in the timing of open orders, (4) cancelation notices indicating that certain open orders have been cancelled due to changes in the MPS, (5) inventor statements, (6) quality reports of different types, indicating cost, item usage, real vs. expected lead times, and so on, (7) exception reports, showing scheduling anomalies, overdue order, scraping, and so on; and (8) stock projections, indicating estimated inventory levels in the future.

The benefits reported by users of MRP systems include: (1) inventory reduction, (2) quicker response to demand changes than is possible with a manual requirements planning system, (3) reduced set-up and material exchange costs, (4) improved machine usage, (5) increased capacity to respond to changes in the master schedule, and (6) assistance in the production of the master schedule.

\subsubsection{Capacity planning}

This is about determining the resources of labor and equipment needed to achieve the master schedule. The original MRP systems developed in the 1970s created schedules that were not always consistent with manufacturing capabilities and plant limitations to make the products.

Capacity planning is often performed in three stages, as shown in Figure 4 first, during aggregate production planning; second, when the master production schedule is set; and third, when the MRP computations are performed.

The term resource requirement planning (RRP) refers to the evaluation process used to ensure that the aggregate project is feasible during aggregate production planning. Next, a capacity analysis called rough-cut power planning (RCCP) is conducted at the MPS level to determine the master schedule's viability. Calculation of third capacity shall be made at the time of preparation of the MRP schedule.

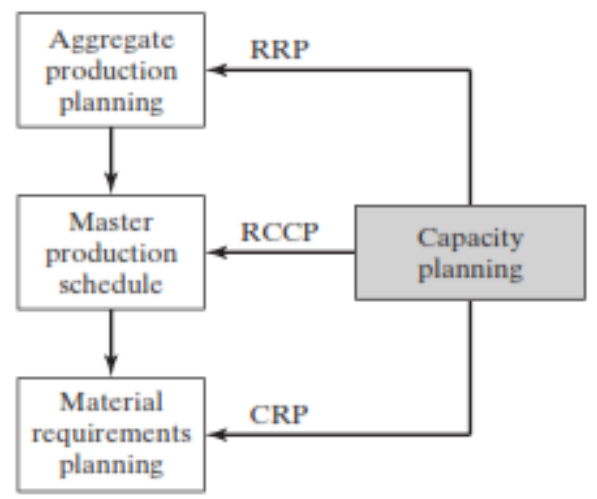

Figure 4 Three stages of capacity planning 
This detailed calculation, called Capacity Requirements Planning (CRP), determines whether the individual departments and work cells have sufficient production capacity to complete the specific parts and assemblies planned by MRP.

The capacity equations indicate possible capacity adjustments. Short-term capacity changes are as follows: employment levels, temporary workers, work shifts, labor hours, inventory stockpiling, order backlogs, subcontracting.

Capacity planning changes for the long term include changes in production capacity that generally require long lead times. Such adjustments include the following actions: new equipment, new plants, purchasing existing plants, acquiring existing companies, closing plants.

\subsubsection{Shop floor control}

Shop floor control (SFC) is a series of production control activities that involve releasing production orders to the warehouse, monitoring and controlling order progress through the different work centers, and collecting current order status information. There are three phases of a standard SFC system: (1) order release (2) order scheduling and (3) order progress.

The three phases of the production management system and their connections to other functions are illustrated in Figure 5. A mixture of software and human resources in modern shop floor control implementations performs both processes, with an increasing proportion being done by machine-automated methods.

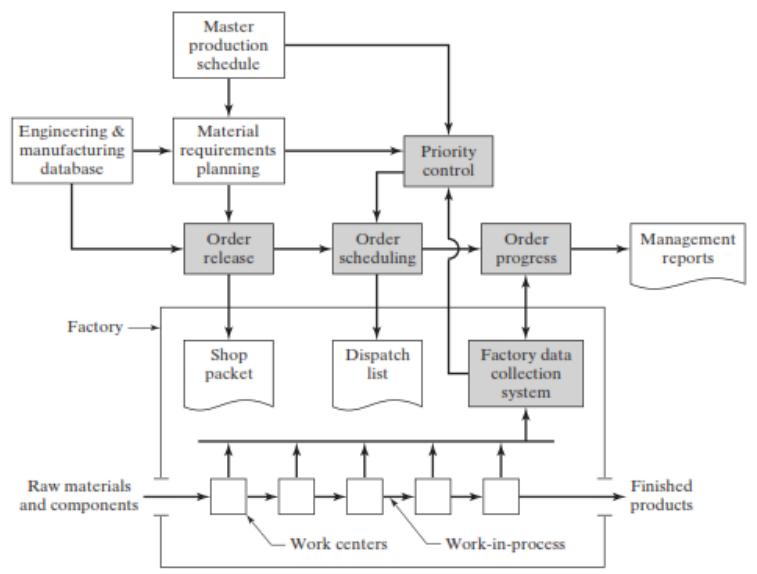

Figure 5 Three phases in a shop floor control system.
The shop floor control phase of order release provides the documentation needed to process a factory production order. Document collection is sometimes called the shop packet. This typically includes: (1) a road map detailing the production plan for the product to be manufactured, (2) material requirements for extracting the required raw materials from the stock, (3) job cards or other means of recording the order's specific working time and showing the progress of the order through the warehouse, (4) moving tickets to allow material handling workers to move parts between plant workplaces where such authorisation is required, and (5) the list of parts where necessary for assembly work.

The order-scheduling phase follows directly from the order release phase and assigns the production orders to the various work centers in the plant. In effect, order scheduling executes the dispatching function in PPC. The order scheduling phase in shop floor control is intended to solve two problems in production control: (1) machine loading and (2) job sequencing.

The order progress phase in the control of the shop floor monitors the status of the different orders in the plant, the work-in-process and other measures indicating production progress. The information submitted to the management of production is often summarized in the form of reports such as: work order status reports, progress reports, exception reports.

The Factory Data Collection System (FDC system) consists of the various paper documents, terminals, and automated devices located throughout the facility to collect data on shop floor operations, as well as the means to compile and process data. As shown in Figure 25.9, the factory data collection process functions as an input to the order progress stage of shop floor operation. Also a priority control input affects the scheduling of orders.

Although a modern FDC system is largely computerized, paper documents are still used in factory operations and both manual (clerical) and automated systems are included in the following coverage.

\subsubsection{Inventory control}

Inventory control attempts to achieve a compromise between two opposing objectives: (1) minimizing the cost of holding inventory and (2) maximizing customer service. Minimizing inventory cost suggests keeping inventory to a 
minimum, in the extreme, zero inventory. Maximizing customer service implies keeping large stocks on hand so that customer orders can immediately be filled. PPC's most interesting inventory types are raw materials, components purchased, in-process inventory (WIP), and finished products. The main inventory holding costs are (1) investment costs, (2) storage costs, and (3) potential obsolescence or spoilage costs. Collectively, the three expenses are referred to as bearing or keeping costs. Cost of investment is usually the most important component.

Two related problems that need to be solved when managing inventories of independent demand items are concerned with order point systems: (1) how many units should be ordered? And (2) when to place the order? The first issue is often solved using economic order quantity formulas. The second problem can be solved with methods of reorder point.

\subsubsection{Manufacturing resource planning (MRP II)}

Manufacturing resource planning can be defined as a computer-based system for planning, planning, and controlling the materials, resources, and supporting activities needed to meet the master production schedule. MRP II is a closedloop process that incorporates and controls the company's major production functions.

MRP II can be considered to consist of three main modules as shown in Figure 6: (1) product specification preparation, or MRP, (2) capability planning, and (3) shop floor management. Based on the master production schedule, the MRP system performs the scheduling role for components, parts, and assemblies, and offers a plant production schedule that suits the delivery of MRP-determined materials.

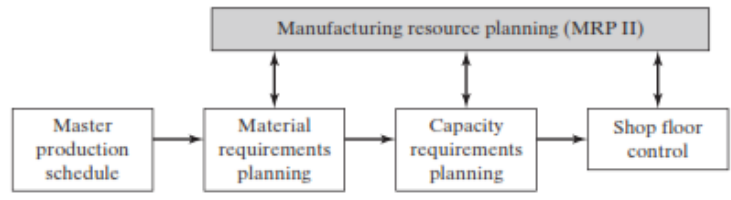

Figure 6 Manufacturing resource planning (MRP II).

The power planning module works with the MRP system to ensure viability of the schedules generated by MRP. Finally, the shop floor control module uses its factory data collection system to perform the feedback control function to implement the three phases of order release, order scheduling and order progress.

\subsubsection{Enterprise resource planning}

Enterprise Resource Planning (ERP) is a computer software system that organizes and manages all of an organization's business functions and related data through a single, central database. Sales, sales, procurement, development, production, delivery, finance, human resources, and more are included in the functions. Through the ERP process, the systems are incorporated to conduct transactions that can affect many operational are as. Figure 7 illustrates how a manufacturing company could organize an ERP program into computer modules.

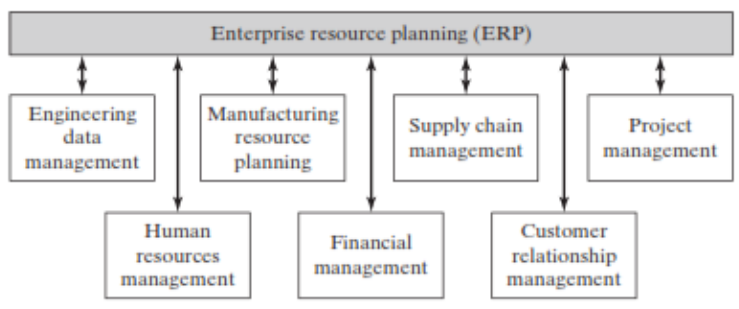

Figure 7 Enterprise resource planning (ERP)

Because it uses a single database, ERP avoids issues such as data redundancy, conflicting data in various databases, and difficulties in communication between different databases and the modules that operate on these databases. The performance in corporate resource management depends on its database's reliability and currency, which ensures that all transactions and incidents impacting the database must be entered when they occur.

\subsection{Just in time and lean production}

Just in time means delivering materials or parts in a manufacturing sequence to the next processing station just before the station needs those parts. It results in a minimum inventory of work-inprocess and encourages high quality in the supplied materials and components. JIT is one of the key methods used in the production system of Toyota. It was called lean production.

\subsubsection{Lean production and waste in manufacturing}

Lean production means using fewer resources to do more work. It is a mass production adaptation in which work is done in less time, in a smaller space, with fewer workers and less equipment, and yet in the final product it achieves higher quality levels. 
The foundation of the Toyota system is at the base of the structure is the elimination of waste in production operations. In production, there is an abundance of waste. Manufacturing activities can be divided into three categories, as Figure 8:

- Actual work consisting of activities that add value to the product

- Auxiliary work that supports the actual valueadding activities.

- Muda, activities that do not add value to the product or promote value-added work

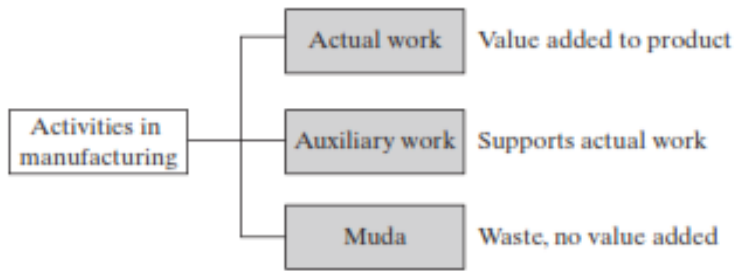

Figure 8 Three categories of activities in manufacturing.

Ohno identified the following seven manufacturing waste forms that he wanted to eliminate through the various Toyota system procedures:

1. Production of defective parts

2. Overproduction, the production of more than the number of items needed

3. Excessive inventories

4. Unnecessary processing steps

5. Unnecessary movement of people

6. Unnecessary transport and handling of materials

7. workers waiting

\subsubsection{Just in time production systems}

To minimize inventories, especially work-inprocess (WIP) systems, just-in-time (JIT) production systems were developed. In the Toyota production system, excessive WIP is seen as waste that should be minimized or removed. The ideal just-in-time manufacturing system produces and delivers exactly the required number of each component in the manufacturing sequence for downstream operation just when that component is needed. This discipline of delivery minimizes lead time for WIP and manufacturing, as well as the space and money invested in WIP.

JIT's key goal is to reduce inventories. Nevertheless, it is not possible to simply require inventory reduction. For a just-in-time production system to function successfully, certain requirements need to be in place. These are (1) a pull system of production control, (2) setup time reduction for smaller batch sizes, and (3) stable and reliable production operations.

JIT is based on a pull system of production control in which the order to produce and deliver parts in the production sequence at each workstation comes from the downstream station using those parts. If the supply of parts is about to be exhausted at a given workstation, that station will order the upstream station to replenish the supply. The upstream station is authorized to produce the required parts only upon receipt of this order. If this process is replicated in the plant at every workstation, it has the effect of pulling parts through the system of production.

The Toyota production system used kanbans (signal card) to implement its pull system. A production control kanban system is based on the use of cards authorizing (1) the production of parts and (2) the distribution of parts in the factory. Thus, there are two types of cards in the conventional implementation of a kanban system: (1) production kanbas and (2) transport kanbas. The upstream station is authorized by a kanban production (P-kanban) to produce a batch of parts. The parts are placed in containers as they are produced, so the batch quantity is just enough to fill the container. It is not permitted to produce more than this quantity of parts in the kanban system. A kanban transport (T-kanban) allows the container of parts to be transported to the downstream station.

To minimize work-in-process inventories in manufacturing, batch sizes and setup times must be minimized. The relationship between batch size and setup time is given by the EOQ (economic order quantity) formula. the EOQ formula is derived, average inventory level is equal to half the batch size. To reduce average inventory level, batch size must be reduced. And to reduce batch size, setup cost must be reduced. This means reducing setup times. Reduced setup times permit smaller batches and lower work-in process levels. Setup time reductions result from a number of basic approaches that are best described as methods improvements.

Certain specifications for a good JIT production system include (1) production leveling, (2) on-time delivery, (3) defect-free components and materials, (4) reliable production equipment, (5) a workforce that is capable, committed, and cooperative, and (6) a dependable supplier base. 


\subsubsection{Autonomation}

Automation is the machines operate autonomously as long as they are functioning properly. When they do not function properly, for example, when they produce a defective part, they are designed to stop immediately. Machinery in the Toyota production system must be reliable, which requires an efficient maintenance program. The following three aspects of automation are covered by this section: (1) stopping the process automatically when something goes wrong, (2) preventing errors and (3) total productive maintenance.

A great deal of autonomation is reflected in the Japanese word jidoka, which refers to machines designed to stop automatically when something goes wrong, such as processing a defective part. Autonomation also refers to machines that are regulated to stop production when the quantity needed (the batch size) has been completed, thus preventing overproduction (one of seven types of waste). It consists of the following control devices: (1) sensors for detecting an irregular operation that would result in a performance deficiency; (2) devices for counting the number of parts produced; and (3) devices for stopping the machine or production line when an unusual operation is detected or the appropriate batch quantity completed.

Error prevention is derived from two Japanese words: poka, meaning mistake, and youth, meaning prevention. Together, poka-yoke means by using low-cost devices to detect and/or prevent errors. Using poka-yoke devices makes it easier for the worker to constantly monitor the process for errors that could lead to defective parts or other unwanted consequences. Most of the functions performed in development by poka-yoke devices can be listed as follows: detecting work part deviations, detecting processing and method deviations, counting and timing functions, verification functions.

Total Productive Maintenance (TPM) is a coordinated group of activities aimed at minimizing production losses due to equipment failures, malfunctions, and low utilization by involving workers at all levels of the organization. Default parts output may be due to incorrect system settings, faulty set-up changes, or inadequate tooling. All these reasons are related to problems with the equipment. Additional reasons for producing defects that may not be related to problems with equipment include faulty starting materials and human error.

\subsubsection{Worker involvement}

Worker involvement in lean development consists of three subjects: (1) quality improvement, (2) visual workplace, and (3) standard work procedures. Therefore, total productive maintenance often includes participation of the employee.

The Japanese word kaizen means continuous improvement of production operations. Kaizen is usually implemented by means of worker teams sometimes called quality circles, which are organized to address specific problems that have been identified in the workplace. The teams deal not only with quality problems, but also with problems relating to productivity, cost, safety, maintenance, and other areas of interest to the organization. Kaizen is a process that seeks to involve all workers as well as their managers and supervisors. Workers are often more than one kaizen circle members. Although the main purpose of organizing workers into teams is to solve production problems, there are other goals that are less evident but also important. Kaizen circles promote the sense of responsibility of the workforce, allow employees to gain acceptance and recognition among colleagues and improve their technical skills.

The idea behind visual management is that only by looking at it should the state of the work situation be clear. If something is wrong, the analyst should be aware of this situation, so that appropriate corrective action can be taken. The theory refers to the whole plant environment, sometimes called the visual workplace. Objects that block the view inside the plant are not allowed, so the entire interior space is clear. Work-in-process build-up is restricted to a specified height. The visual workplace, therefore, provides visibility throughout the plant and promotes good housekeeping. A $5 \mathrm{~S}$ method, a series of procedures used to coordinate work areas in the factory, is one way to engage workers in the visual workplace. Worker teams are usually made responsible for completing the steps, and the $5 \mathrm{~S}$ method must be an ongoing process to support the accomplishments made. The five steps in $5 \mathrm{~S}$ with the Japanese word in parentheses are as follows: sort (seiri), set in order (seiton), shine (seiso), standardize (seiketsu), self-discipline (shitsuke). 
The Toyota production system establishes standardized work procedures is used to determine the duration of the work cycle to be completed. Toyota's aims of using uniform job procedures are: increase productivity, balance the workload, and minimize work-in process. For a given task, a standardized work process has three components: (1) cycle time, (2) work sequence and (3) standard work-in-process quantity. Such components are recorded using methods that illustrate the special manufacturing procedures of Toyota. Sometimes the forms are quite different from those used in the engineering and work measurement of traditional methods.

The cycle time is the average time it takes for a given process to be completed. Using a stopwatch time study, this time is established. The cycle time is documented in the part production capacity chart. Takt time, the reciprocal demand rate for a given product or part, calculated for the available shift time in the factory (takt is a German word meaning cadence or pace) is closely related to the cycle time. The takt time offers a specification for the component or product based on demand. The research is planned in the Toyota production system to synchronize the operating cycle time with the takt time. This is achieved by planning the sequence of work and standardizing the quantity of work-in-process.

The sequence of work, also known as the standard operations routine, is the order of work elements or operations performed by a given worker to perform an assigned task. For a given process, the cycle time may differ from the takt time, which is based on the demand for the item produced in the task and not on the task itself requirements. Attempts are made in the Toyota system to arrange the work in such a way that for each processing phase the cycle time is equal to the part's takt time. When the cycle times match the takt time, all the processes in the sequence are balanced, minimizing the amount of work-inprocess. The functions were built into the work cells in the Toyota production system. A working cell at Toyota is a group of physically arranged workers and processing stations in sequential order so that parts can be produced in small batches, often one at a time. Usually, the cells are U-shaped rather than straight for the purpose of promoting co-workership and maintaining continuous work flow in the cell.

The standard work-in-process quantity is the minimum number of parts necessary to avoid workers waiting. Factors that tend to influence how many work parts in a given work cell should be defined as the quantity of stan-dard work-inprocess parts include:

- If quality inspections are to be carried out as separate measures, additional parts for these inspections must be provided,

- If the manufacturing involves heating of the parts (e.g. hot forging), then additional heating time and cooling time must be required for WIP.

- If the worker's work sequence is in the opposite direction of the part processing sequence, then at least one part of the work between machines must be held in order to avoid waiting.

\section{CONCLUSION}

Production planning and control system is a tool for manufacture industry to produce a part or final product. Activities in production planning namely: aggregate production planning, master production planning, material requirement planning, capacity planning. For activities in production control are shop floor control, inventory control, manufacturing resource planning, enterprise resource planning.

Lean production that evolved by Toyota manufacturing is a method of production. It contain several system likely elimination of waste as base structure, just in time (JIT) production and autonomation as a pillars, and worker involvement between two pillars. Thus, goal of lean production is customer satisfaction.

\section{ACKNOWLEDGEMENT (IF ANY)}

This paper submitted as an assignment of automation manufacture system lecture.

\section{REFERENCES}

[1] M. . Groover, Automation, production system, and computer-integrated manufacturing, 4th editio. Pearson, 2015.

[2] R. Ulewicz, D. Jelonek, and M. Mazur, "IMPLEMENTATION OF LOGIC FLOW IN PLANNING AND PRODUCTION CONTROL," vol. 7, no. 1, pp. 89-94, 2016.

[3] D. T. J. J.P. Womack, "Lean Production to the Lean Enterprise Harvard Business Review," vol. 72, no. 2, pp. 93-103, 1994.

[4] J. P. Womack and D. T. Jones, "Lean Thinking-Banish Waste and Create Wealth 
in your Corporation,” J. Oper. Res. Soc., vol. 48, no. 11, pp. 1148-1148, 1997.

[5] B. A. Henderson and J. . Larco, "Lean Transformation: How to change your business into a lean enterprise," in Lean Transformation, no. Oaklea Press, 2003, pp. 180-188.

[6] N. Kumar, S. Kumar, A. Haleem, and P. Gahlot, "Implementing lean manufacturing system: ISM approach," J. Ind. Eng. Manag., vol. 6, no. 4, pp. 996-1012, 2013.

[7] R. Shah and P. T. Ward, "Defining and developing measures of lean production," J. Oper. Manag., vol. 25, no. 4, pp. 785-805, 2007.
[8] S. Bhasin and P. Burcher, "Lean viewed as a philosophy," J. Manuf. Technol. Manag., vol. 17, no. 1, pp. 56-72, 2006.

[9] M. Holweg, "The genealogy of lean production," J. Oper. Manag., vol. 25, no. 2, pp. 420-437, 2007.

[10] A. Javadian Kootanaee, K. N. Babu, and H. F. Talari, "Just-In-Time Manufacturing System: From Introduction to Implement," SSRN Electron. J., vol. 1, no. 2, pp. 7-25, 2013 